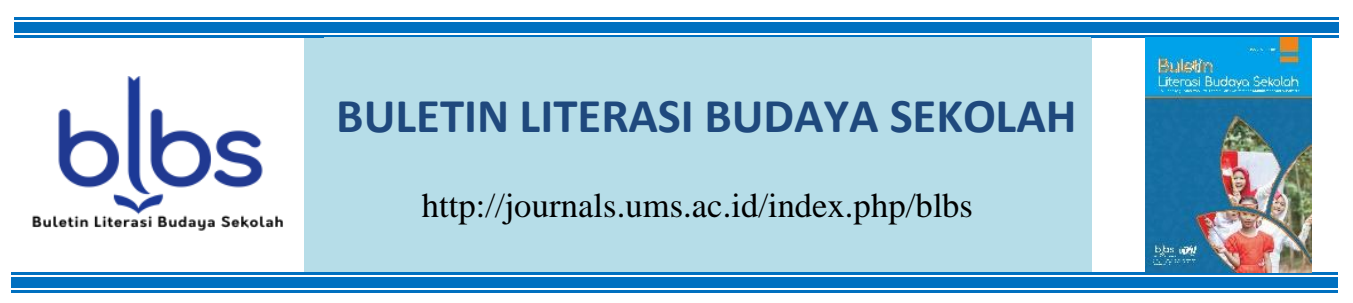

\title{
REALISASI GERAKAN LITERASI DIGITAL SEBAGAI IMPLEMENTASI GERAKAN LITERASI NASIONAL DI SEKOLAH MUHAMMADIYAH PANGKALAN BUN
}

\author{
Izzah Iswara Mundhofir Putri ${ }^{1}$, Ermiyanti ${ }^{2}$, \& Endang Rahayu Ningsih ${ }^{3}$ \\ ${ }^{1}$ Universitas Muhammadiyah Surakarta \\ ${ }^{2}$ SMP Muhammadiyah Pangkalan Bun \\ ${ }^{3}$ SMK Muhammadiyah Pangkalan Bun \\ Universitas Muhammadiyah Surakarta, Surakarta, Indonesia \\ Email \& Phone: a310160199@student.ums.ac.id +6285740002811
}

Submitted: $2020-08-19$

Accepted: 2020-09-09

Published: 2020-12-07

\begin{tabular}{ll}
\hline Keywords: & Abstract \\
\hline digital literacy & The problem of this research is how the realization of the digital \\
national & literacy movement as a form of implementation of GLN in \\
literacy & Muhammadiyah Pangkalan Bun School and what factors influence \\
movements & the implementation of digital literacy at Muhammadiyah Pangkalan \\
muhammadiyah & Bun School. This research method is descriptive qualitative, which \\
school & describes factually the factors that influence the implementation of \\
& digital literacy at Muhammadiyah Pangkalan Bun School. Data \\
& collection was carried out by means of observation, interview and \\
& questionnaire distribution. The data analysis of this research was \\
& carried out inductively, namely the analysis technique that went from \\
& fact to theory. This study uses theoretical triangulation, which is to \\
& double-check the validity of the research data with existing related \\
& theories. The results of this study indicate that digital literacy at \\
& Muhammadiyah Pangkalan Bun School is realized in the form of \\
& hardware such as laptops, projectors, speakers, and WiFi. Several \\
& factors influence the implementation of digital literacy, namely: (1) \\
& The location of the school which is the access in and out of the \\
general public. (2) The location of the school which is one area with \\
a lower level of school (TK ABA, SD Muhammadiyah Pangkalan \\
Bun, SMP Muhammadiyah Pangkalan Bun). (3) Different students' \\
backgrounds.
\end{tabular}

\section{PENDAHULUAN}

Perkembangan teknologi terjadi lebih pesat pada satu dekade terakhir. Manusia masa kini dituntut untuk memiliki kemampuan dan kecakapan sebagai bekal untuk menghadapi revolusi abad ke-21. Kemampuan tersebut harus dilengkapi dengan keterampilan-keterampilan dan kecakapan lain yang tidak hanya berlandaskan pada konsep literasi secara klasik. 
Secara umum literasi digital yaitu suatu kemampuan seseorang dalam memanfaatkan teknologi dengan tujuan untuk menganalisis, menggunakan, membuat, menemukan, dan mengomunikasikan informasi dengan kecakapan kognitif maupun kecakapan teknikal (Syaripudin dkk, 2020:4). Menurut buku klasik Gilster dalam (Nasrullah dkk, 2020:7) literasi digital dimaknai sebagai kemampuan seseorang dalam memahami dan menggunakan teknologi informasi yang disesuaikan dengan prosedur yang berlaku dari berbagai sumber yang disajikan dalam komputer. Harjono (2020:4) mendefinisikan literasi digital sebagai perpaduan dari keterampilan memanfaatkan teknologi, berpikir kritis, keterampilan bekerja sama, dan kesadaran sosial, di mana keempat aspek tersebut saling berhubungan dengan keterampilan-keterampilan fungsional yang bertautan dengan pengetahuan dan penggunaan media digital secara efektif dan efisien. Dalam literasi digital seseorang tidak hanya dituntut untuk memiliki kemampuan untuk mencari, menggunakan dan menyebarkan informasi, tetapi dapat membuat dan mengevaluasi secara kritis informasi isi dari informasi yang terkandung di dalam konten digital (Liansari dan Nuroh, 2020:244). Manfaat penggunaan teknologi digital menurut (Gracia dkk, 2020) antara lain (1) mempermudah individu dalam menemukan informasi, (2) mempermudah dalam berkomunikasi, (3) meningkatkan kreativitas, (4) mempermudah kegiatan belajar.

Sitting alongside the corpus of work on critical engagement with digital media is a morerecent perspective on how key issues of digital literacy can be addressed. The 'designturn' in literacy studies loosely refers to the idea that unpacking and examining theprocesses of digital design in an educational setting lead the learner to a critical andpractical knowledge of digital text production - a critical digital literacy (Pangrazio, 2020:166). Sebuah studi yang dilakukan oleh Asosiasi Perguruan Tinggi dan Universitas Amerika mengungkapkan bahwa lulusan baru harus lebih siap sebagai pemikir kritis (Alexander, 2020:1). Berdasarkan penelitian tahun ini, keterampilan digital sangat dibutuhkan dalam proses pembuatan perangkat digital sebagaimana mencakup alat produktivitas kantor; pembuatan, dan pengeditan media (gambar, audio, video); keterampilan web (menulis dan mencari); keterampilan media hardware (perangkat keras komputer, pencetakan 3D); dan bidang yang muncul (VR, AR, MR) tetap berfungsi sebagaimana mestinya (Alexander, 2020:13).

Berdasarkan program Kemdikbud Gerakan Literasi Nasional dikembangkan dari sembilan agenda prioritas pemerintah yang dikenal dengan sebutan Nawacita. Berkaitan dengan program GLN, Nawacita nomor (5) meningkatkan kualitas hidup masyarakat Indonesia; (6) meningkatkan daya saing dan produktivitas rakyat di kancah internasional sehingga menjadikan negara Indonesia sebagai bangsa yang maju bersama bangsa-bangsa lain di Asia; (8) melaksanakan gerakan perubahan karakter bangsa; (9) memperkuat kebinekaan dan restorasi sosial Indonesia. Empat butir Nawacita tersebut tercermin ke dalam sikap manusia yang unggul, produktif, berkualitas, memiliki daya saing, dan berkarakter melalui implementasi kegiatan literasi (Hidayah, Widodo, dan Sueb, 2020:88).

Gerakan Literasi Nasional adalah sebuah upaya untuk menggiatkan seluruh potensi dan memperluas keterlibatan masyarakat dalam membudayakan dan menumbuhkembangkan literasi di Indonesia (Atmazaki dkk, 2020:5). Menurut Ibrahim dkk (2020:3) GLN merupakan suatu upaya guna memperkuat dan 
menggiatkan semua pelaku gerakan literasi dengan melibatkan potensi publik dalam menumbuhkembangkan budaya literasi. Tujuan utama dari adanya Gerakan Literasi Nasional adalah untuk menumbuhkan serta mengembangkan budaya literasi di lingkungan pendidikan, baik di lingkungan keluarga, sekolah, dan masyarakat dalam rangka mewujudukan karakter belajar sepanjang hayat sebagai usaha untuk meningkatkan kualitas hidup (Atmazaki dkk, 2020:5).

Sekolah Muhammadiyah adalah sekolah berbasis islam yang menyelenggarakan pendidikan berdasarkan agama islam yang luas dan mendalam meliputi tauhid, ibadah, akhlak, dan ilmu islam lainnya yang berkontribusi dalam pendidikan islam termasuk kemuhammadiyahan (Marlina, 2020: 114). Sehingga target yang harus dicapai oleh setiap lulusan pendidikan muhammadiyah yaitu akidah yang baik, akhlah yang muliah, terampil, cerdas, dan memiliki jiwa pengabdian masyarakat (Yusra, 2020:114-115). Berdasarkan Rakernas (Rapat Kerja Nasional) Majelis Dikdasmen PP Muhammadiyah berkaitan dengan visi fungsi pendidikan dasar dan menengah Muhammadiyah mencakup sekolah, madrasah dan pesantren yang berbasis Al-Islam Kemuhammadiyahan, holistik integratif, memiliki tata kelola yang baik, unggul serta berdaya saing yang tinggi. Tiga cakupan tersebut sebagai tolok ukur berkembangnya fungsi pendidikan sekolah muhammadiyah (Ali, 2020:32).

Pesatnya perkembangan teknologi memberikan pengaruh besar terhadap dunia pendidikan. Pengaruh tersebut menuntut guru untuk dapat memanfaatkan teknologi ke dalam pembelajaran sebagai media digital. Pemanfaatan teknologi ini sebagai faktor munculnya istilah literasi digital yang mendorong pembelajaran aktif menggunakan sistem pemrosesan digital, konstruksi ilmu pengetahuan, pembelajaran inquiri, dan eksplorasi para peserta didik. Literasi digital yang mencakup teknologi informasi dan komunikasi baru seperti internet, game online, kecerdasan buatan, robotika, dan percetakan 3D membutuhkan literasi baru (literasi digital). Beberapa tahun terakhir ini kompetensi digital telah membentuk konsep dalam diskusi tentang keterampilan dan pemahaman yang dibutuhkan oleh peserta didik dalam masyarakat luas.

Berbagai penelitian dalam bidang pendidikan memperlihatkan bahwa dalam memanfaatkan teknologi secara efektif seorang pembelajar tidaklah cukup jika hanya mengandalkan literasi, melainkan memerlukan aspek lain yang mendukung kompetensi. Oleh karena itu diperlukan literasi baru yaitu literasi digital. Tujuan penelitian ini adalah untuk mengidentifikasi realisasi gerakan literasi digital sebagai wujud implementasi GLN di Sekolah Muhammadiyah Pangkalan Bun dan faktor-faktor yang memengaruhi implementasi literasi digital di Sekolah Muhammadiyah Pangkalan Bun. Penelitian ini menyajikan pandangan baru mengenai realisasi gerakan literasi digital dan faktor-faktor yang memengaruhi implementasi gerakan literasi nasional.

\section{METODE}

\section{Jenis dan Desain Penelitian}

Jenis penelitian ini adalah deskriptif kualitatif, yaitu mendeskripsikan secara faktual realisasi gerakan literasi digital dan faktor-faktor yang memengaruhi implementasi literasi digital di Sekolah Muhammadiyah Pangkalan Bun. Sedangkan desain penelitian ini menggunakan pendekatan studi kasus. Metode penelitian 
Izzah Iswara Mundhofir Putri ${ }^{1}$, Ermiyanti ${ }^{2}$, \& Endang Rahayu Ningsih ${ }^{3}$ Realisasi Gerakan Literasi Digital

kualitatif diartikan sebagai suatu kegiatan penelitian yang mengutamakan data gabungan yang diperoleh dari penelitian lapangan dan diwujudkan dalam bentuk kata, frasa, klausa, kalimat, wacana untuk dikumpulkan ke dalam purposive sampling dan menggunakan prosedur ilmiah secara sistematis, sehingga penelitian kualitatif lebih mengedepankan makna daripada menyimpulkan hasil penelitian (Rohmadi dan Nasucha, 2020:24).

\section{Tempat dan Waktu Penelitian}

Tempat penelitian dilaksanakan di SMP Muhammadiyah Pangkalan Bun dan SMK Muhammadiyah Pangkalan Bun, Kecamatan Arut Selatan, Kabupaten Kotawaringin Barat. Waktu penelitian dilakukan selama 6 bulan, yaitu terhitung mulai konsultasi, pengajuan judul, hingga penulisan laporan penelitian. Berikut rincian waktu penelitian yang disajikan dalam bentuk tabel sebagai berikut.

\begin{tabular}{|c|c|c|c|c|c|c|c|c|c|c|c|c|c|c|c|c|c|c|c|c|c|c|c|c|c|c|}
\hline \multirow{4}{*}{ No } & \multirow{4}{*}{ Kegiatan } & \multicolumn{25}{|c|}{ Bulan ke- } \\
\hline & & \multicolumn{4}{|c|}{1} & \multicolumn{4}{|c|}{2} & \multicolumn{4}{|c|}{3} & \multicolumn{5}{|c|}{4} & \multicolumn{4}{|c|}{5} & \multicolumn{4}{|c|}{6} \\
\hline & & \multicolumn{25}{|c|}{ Minggu ke- } \\
\hline & & 1 & 2 & 3 & 4 & 1 & 2 & 3 & 4 & 1 & 2 & 3 & 4 & 1 & & & & 4 & 1 & 2 & 3 & 4 & 1 & 2 & 3 & 4 \\
\hline 1 & $\begin{array}{l}\text { Konsultasi } \\
\text { pengajuan } \\
\text { judul } \\
\text { skripsi }\end{array}$ & & & & & & & & & & & & & & & & & & & & & & & & & \\
\hline 2 & $\begin{array}{l}\text { Pengajuan } \\
\text { proposal } \\
\text { skripsi }\end{array}$ & & & & & & & & & & & & & & & & & & & & & & & & & \\
\hline 3 & $\begin{array}{l}\text { Pengumpu } \\
\text { lan data }\end{array}$ & & & & & & & & & & & & & & & & & & & & & & & & & \\
\hline 4 & $\begin{array}{l}\text { Bimbingan } \\
\text { dan } \\
\text { konsultasi }\end{array}$ & & & & & & & & & & & & & & & & & & & & & & & & & \\
\hline 5 & Revisi & & & & & & & & & & & & & & & & & & & & & & & & & \\
\hline 6 & $\begin{array}{l}\text { Penyelesai } \\
\text { an skripsi }\end{array}$ & & & & & & & & & & & & & & & & & & & & & & & & & \\
\hline
\end{tabular}

Table 1 Tabel 1. Rincian waktu penelitian

\section{Objek dan Subjek Penelitian}

Objek penelitian ini adalah literasi digital di SMP Muhammadiyah Pangkalan Bun dan SMK Muhammadiyah Pangkalan Bun. Sedangkan subjek penelitian ini adalah siswa kelas VII A dan VIII SMP Muhammadiyah Pangkalan Bun, siswa kelas XI Multimedia 2 dan XII Multimedia 2 SMK Muhammadiyah Pangkalan Bun, Guru bahasa Indonesia SMP Muhammadiyah Pangkalan Bun, dan Guru Bahasa Indonesia SMK Muhammadiyah Pangkalan Bun.

\section{Data dan Sumber Data}

Data penelitian ini adalah literasi digital di Sekolah Muhammadiyah Pangkalan Bun, sumber data penelitian ini adalah hasil observasi dan wawancara bersama guru Bahasa Indonesia SMP dan SMK Muhammadiyah Pangkalan Bun.

\section{Teknik Pengumpulan Data}

Pengumpulan data dilakukan dengan teknik observasi, wawancara, dan penyebaran angket. Teknik observasi dilakukan secara bertahap selama 6 minggu, yaitu dengan cara mengamati kegiatan literasi digital di lingkup Sekolah 
Muhammadiyah Pangkalan Bun. Teknik wawancara dilakukan bersama dengan guru Bahasa Indonesia SMP Muhammadiyah dan SMK Muhammadiyah Pangkalan Bun. Penyebaran angket meliputi siswa kelas VII A dan VIII SMP Muhammadiyah Pangkalan Bun, siswa kelas XI Multimedia 2 dan XII Multimedia 2 SMK Muhammadiyah Pangkalan Bun.

\section{Teknik Analisis Data}

Analisis data pada penelitian ini dilakukan secara induktif, yaitu teknik analisis yang berlangsung dari fakta ke teori. Teknik analisis ini dilakukan untuk menghindari manipulasi data seperti profil pemakaian bahasa, termasuk juga tidak mengungkap faktor-faktor yang memengaruhi pemakaian bahasa tersebut secara memadai dan objektif. Menganalisis berarti menguraikan secara rinci unsur-unsur pembentuk satuan lingual yang diuraikan ke dalam komponen-komponennya (Rohmadi dan Nasucha, 2020:35).

\section{Prosedur Penelitian}

Penelitian dilakukan dengan teknik observasi di SMP Muhammadiyah Pangkalan Bun dan SMK Muhammadiyah Pangkalan Bun. Melakukan wawancara bersama narasumber terkait meliputi Guru Bahasa Indonesia SMP Muhammadiyah Pangkalan Bun dan Guru Bahasa Indonesia SMK Muhammadiyah Pangkalan Bun. Melakukan penyebaran angket dengan siswa kelas VII A dan VIII SMP Muhammadiyah Pangkalan Bun, siswa kelas XI Multimedia 2 dan XII Multimedia 2 SMK Muhammadiyah Pangkalan Bun. Teknik tersebut dilakukan untuk mendapatkan data yang akurat berdasarkan fakta.

\section{Keabsahan Data}

Dalam menguji validitas data dapat menggunakan trianggulasi. Trianggulasi secara umum dibagi ke dalam empat macam, yakni trianggulasi data atau sumber, trianggulasi peneliti, trianggulasi teori, dan trianggulasi metode. Penelitian ini menggunakan trianggulasi teori, yakni mengecek kembali validitas data penelitian dengan teori-teori terkait yang sudah ada. Trianggulasi yang digunakan oleh peneliti mengacu pada lebih dari satu teori dalam membahas setiap permasalahan yang akan dikaji (Rohmadi dan Nasucha, 2020:33).

\section{HASIL DAN PEMBAHASAN}

\section{HASIL PENELITIAN}

\section{Realisasi Literasi Digital di SMP Muhammadiyah Pangkalan Bun}

Berdasarkan hasil wawancara, literasi digital di SMP Muhammadiyah Pangkalan Bun direalisasikan dalam wujud perangkat keras seperti laptop, proyektor, speaker, WiFi. Namun dalam ketersediaan fasilitas tersebut masih sangat terbatas. Sekolah hanya memiliki 1 speaker, 4 unit proyektor, dan $1 \mathrm{WiFi}$ yang diletakkan di area tertentu saja. Dalam penggunaan speaker digunakan secara bergantian, mengingat jumlah speaker yang ada di sekolah hanya tersedia 1 unit saja. Bagi guru yang membutuhkan speaker sebagai media pembelajaran lebih memilih membawa speaker pribadi ke sekolah untuk mengantisipasi penggunaan speaker yang secara bersamaan.

Beberapa materi dalam mata pelajaran Bahasa Indonesia terkait dengan realisasi literasi digital di SMP Muhammadiyah Pangkalan Bun yaitu (1) kelas IX teks cerita inspirasi, (2) kelas VIII teks persuasif dan teks ulasan, (3) kelas VII teks cerita fantasi dan laporan hasil observasi. Ketiga materi pelajaran tersebut dapat 
memanfaatkan media digital seperti laptop dan speaker. Dalam mengajarkan KD Mengidentifikasi ciri teks, metode yang digunakan yaitu dengan memutarkan film yang berkaitan dengan jenis teks. Peserta didik diminta untuk mengidentifikasi ciri teks tersebut, kemudian hasil dari identifikasi ditempelkan ke papan tulis untuk di analisis bersama. Peserta didik juga diajarkan untuk membuat email dan mengumpulkan tugas melalui email. Salah satu kegiatan yang memanfaatkan email sebagai media pengumpulan tugas yaitu prakarya dan video.

Berdasarkan hasil observasi, pembelajaran bahasa Indonesia di ruang kelas VIII SMP Muhammadiyah Pangkalan Bun menggunakan media digital berupa laptop, speaker, dan proyektor. Guru mengajarkan teks persuasif dengan menggunakan media audio yang berbentuk rekaman teks persuasif. Siswa mendengarkan rekaman teks persuasif tentang meningkatkan minat baca di Banyuwangi yang diunduh di diskusibanyuwangi.co.id pada tahun 2017. Siswa diminta untuk menuliskan kalimat yang mengandung ajakan. Berdasarkan rekaman kalimat yang mengandung kalimat ajakan yaitu "mengajak anak-anak untuk membaca".

Berdasarkan hasil penyebaran angket, fasilitas komputer di sekolah belum mencukupi. Begitu pula siswa dilarang membawa laptop ke sekolah apabila tidak ada kepentingan. Siswa diperbolehkan membawa laptop ke sekolah apabila ada kepentingan seperti mengerjakan tugas dan presentasi. Hal ini dilakukan supaya tidak terjadi kehilangan, mengingat lokasi sekolah yang masih menjadi lalu lalang masyarakat umum.

LCD dan speaker belum dipasang di setiap ruang kelas. Sekolah hanya memiliki LCD sebanyak 4 unit yang diletakkan di ruang guru. Sekolah juga hanya memiliki 1 speaker. Apabila hendak menggunakan harus bergantian dengan guru mata pelajaran lain.

Keamanan sekolah juga belum difasilitasi dengan CCTV. Sehingga dikhawatirkan jika akan terjadi kasus pencurian. Sekolah sudah menyediakan fasilitas jaringan internet WiFi di ruang guru. Siswa tidak bisa memanfaatkan fasilitas tersebut secara optimal, dikarenakan anjuran guru untuk membawa laptop pada saat presentasi dan kebutuhan penting saja. Siswa juga dilarang membawa gawai ke sekolah, mengingat ada banyak faktor yang timbul karena penggunaan gawai sehingga sekolah tidak memberikan izin untuk pemakaian gawai tersebut.

Banyak siswa yang tidak memahami buku elektronik, bahkan ada yang tidak mengetahuinya. Beberapa siswa juga tidak memiliki email, banyak di antaranya yang tidak memahami cara menggunakannya. Siswa juga belum diajarkan memanfaatkan aplikasi online sebagai sarana penugasan dan pengumpulan tugas.

\section{Realisasi Literasi Digital di SMK Muhammadiyah Pangkalan Bun}

Berdasarkan hasil wawancara, literasi digital di SMK Muhammadiyah Pangkalan Bun direalisasikan dalam bentuk perangkat keras seperti laptop, WiFi, speaker, dan proyektor. Internet disediakan oleh sekolah yang hanya bisa diakses di kelas XII Multimedia dan X Mulitmedia. Karena kebutuhan peserta didik Multimedia sangat penting demi kelancaran pembelajaran di kelas tersebut. Dalam pembelajaran, tidak semua jurusan di SMK Muhammadiyah Pangkalan Bun menggunakan peralatan digital, hanya jurusan Multimedia dan mata pelajaran Multimedia saja yang diutamakan menggunakan peralatan digital. 
Adapun pada saat pembelajaran, siswa lebih senang jika diambilkan contoh yang tidak jauh dari bidang pekerjaannya. Sehingga ketika peserta didik naik ke kelas 11 , hasil penugasannya bisa menjadi contoh bagi kelas 10 peserta didik yang baru, dari situ bisa menjadi kritikan dan masukan bagi kelas 10 untuk membuat video yang lebih baik lagi. Pada intinya menjadi guru juga perlu mendidik siswa menjadi dewasa, ketika mereka melakukan kesalahan mereka mengetahui kesalahannya dan mereka mencoba memperbaikinya. Tetapi untuk menjadi sempurna membutuhkan latihan yang berulang-ulang, artinya bukan hanya satu angkatan, tetapi juga bergerak ke angkatan selanjutnya.

Peserta didik lebih tertarik dengan media audiovisual yang berupa tayangan daripada harus membaca. Kebetulan di SMK lebih banyak materi bahasa dan bukan sastra. Di SMK terdapat lima modul, empat modul kebahasaan, satu modul sastra. Sehingga peserta didik di SMK lebih banyak menjumpai teks kebahasaan seperti teks prosedur dan eksplanasi daripada teks sastra seperti novel, cerpen, dan pantun. Karena peserta didik di SMK rata-rata siap kerja sehingga yang mereka butuhkan sesuai dengan bidang kerja mereka.

Karakter anak setiap kelas berbeda-beda. Anak Multimedia memiliki karakter santai, mereka tidak hebat, juga tidak rendah sekali. Ibarat anak Farmasi jika mengoperasikan laptop tidak sehebat anak Multimedia, begitu juga jika menggunakan cangkul tidak akan sehebat anak Pertanian. Oleh karena itu dalam memperlakukan setiap kelas tidak bisa sama. Farmasi memiliki karakter serius dan lebih gesit karena menghadapi pembelajaran yang sulit. Pertanian lebih banyak menggunakan fisik dan banyak gerak, sedangkan Multimedia menyukai edit dan produksi video.

Di antara semua jurusan di SMK guru jarang menggunakan media digital dalam pembelajaran dan lebih memilih mendatangi siswanya. Alasannya adalah ketika jurusan Pertanian setelah melakukan kegiatan lapangan dikhawatirkan tertidur dan tidak fokus lagi dalam belajar, begitu juga siswa jurusan Farmasi, guru lebih banyak menggunakan media digital di jurusan Multimedia. Sehingga alasannya secara umum ada perbedaan dari siswa satu dengan siswa lainnya, dari lingkungan, dan latar belakang siswa.

Pada saat mengajar di kelas X Multimedia, peserta didik diminta untuk membuat video tentang teks negosiasi. Guru ingin melihat seberapa jauh kemampuan produktif mereka dalam menghasilkan video yang baik. Dari situ guru menjadi tahu seberapa besar kemampuan mereka dalam menerapkan ilmu yang mereka dapat. Minimal seorang anak masuk ke jurusannya karena menyukai bidangnya terlebih dahulu dan bukan karena paksaan. Jika seorang anak menyukai bidangnya maka dia sudah memiliki bakat sebelumnya.

Dalam mengedit video peserta didik diberikan waktu 1 minggu. Guru juga harus melihat kondisi siswa, jika peserta didik tertekan maka hasilnya menjadi kurang baik. Walaupun peserta didik dibatasi dalam teknologi digital, mereka tetap senang ke sekolah. Karena alasannya dahulu banyak sekali yang memiliki videovideo dewasa, chatingan-chatingan yang isinya mengarah ke hal-hal yang tidak sesuai dengan usia peserta didik. Yang pertama sekolah berpegang bahwa basic perguruan Muhammadiyah adalah sekolah islam, setidaknya perilaku warga sekolah juga mencerminkan sebagai siswa yang muslim dan muslimah. 
Berdasarkan hasil observasi, pembelajaran Bahasa Indonesia di kelas $\mathrm{X}$ Multimedia 1 sudah mencerminkan pembelajaran berbasis digital. Peserta didik diminta untuk menampilkan hasil pembuatan video berdurasi 5-10 menit dengan tema teks negosiasi. Penugasan diberikan 1 minggu sebelum dipresentasikan. Dalam video harus mencerminkan percakapan negosiasi, baik ditampilakan melalui tindakan maupun melalui percakapan. Siswa dibagi ke dalam kelompok-kelompok yang beranggotakan 4-5 orang. Video terbaik akan mendapat apresiasi dan penghargaan dari guru. Sehingga video-video yang telah dibuat dapat dijadikan sebagai referensi bagi peserta didik baru yang akan datang.

\section{PEMBAHASAN}

\section{Realisasi Gerakan Literasi Digital di SMP Muhammadiyah Pangkalan Bun}

Berdasarkan hasil penelitian, pembelajaran di SMP Muhammadiyah Pangkalan Bun sudah merealisasikan pembelajaran berbasis digital. Guru sebagai fasilitator mengupayakan kegiatan pembelajaran yang menarik dengan menyediakan laptop, speaker, dan LCD dalam mengajarkan teks persuasif. Guru menggunakan media audio dengan memperdengarkan rekaman teks persuasif tentang "Meningkatkan Minat Baca di Banyuwangi". Kegiatan ini dapat melatih kemampuan menyimak siswa untuk menangkap $5 \mathrm{~W} 1 \mathrm{H}$ yang terdapat dalam rekaman. Sehingga siswa dapat mendeskripsikan kembali teks yang didengar dengan menggunakan kalimatnya sendiri.

Dengan upaya guru yang berusaha menyajikan pembelajaranpembelajaran menarik dari sumber belajar bervariasi dapat meningkatkan kemampuan siswa dalam pembelajaran Bahasa Indonesia di dalam kelas. Tapi kegiatan ini tidaklah lengkap tanpa diimbangi dengan kompetensi siswa di bidang digital. Untuk menggerakkan budaya literasi, siswa juga perlu diajarkan untuk membuka jendela literasi digital dengan upaya lain yang dapat menarik minat siswa untuk mau mencoba. Misalnya, mengajarkan siswa untuk membuat email, kemudian meminta siswa untuk mengumpulkan tugas melalui email. Kegiatan ini dapat membuka jendela literasi digital siswa agar mau mencoba.

Upaya lain adalah menampilkan wujud buku elektronik yang bisa didapatkan dengan mudah oleh siswa di internet. Membaca melalui buku-buku elektronik kemudian meminta siswa untuk mendeskripsikan kembali menggunakan bahasa sendiri, ditulis dalam format doc, dan dikirim melalui email. Sehingga dengan kegiatan ini dapat memanfaatkan email sebagai media penugasan dan pengumpulan tugas. Selain itu, guru juga dapat mengakses aplikasi online seperti schoology dan google classroom yang dapat digunakan sebagai media penugasan lain. Kegiatan ini akan semakin memperkaya literasi digital peserta didik, sehingga peserta didik dapat mengikuti perkembangan teknologi secara baik dan mampu bersaing di dunia global.

Namun kegiatan itu tidaklah lengkap apabila tidak diimbangi dengan fasilitas yang menunjang. Ruang komputer dan penyediaan WiFi juga sangat dibutuhkan untuk mengakses berbagai situs-situs resmi untuk menyaring informasi yang akurat. Peserta didik juga perlu mengetahui perbedaan sumber informasi yang resmi atau tidak, sehingga tidak menelan mentah-mentah informasi yang didapatkan. Kegiatan ini juga dapat mengurangi penyebaran berita hoaks yang marak di kalangan remaja. 
Berkaitan dengan teori Ginanjar (2020:100) bahwa dalam dunia pendidikan, literasi digital di sekolah harus disesuaikan dengan kebutuhan peserta didik. Adapun 3 komponen yang harus dipenuhi dalam literasi digital di sekolah yaitu:

a. Kemampuan dalam memanfaatkan teknologi secara baik;

Berdasarkan hasil observasi di SMP Muhammadiyah Pangkalan Bun kemampuan peserta didik dalam mengoperasikan perangkat digital sudah cukup baik, meskipun belum dimanfaatkan secara optimal peserta didik secara umum telah bergerak pada literasi digital. Penggunaan gawai di sekolah memang merupakan sebuah larangan dan aturan yang harus ditaati. Di samping larangan membawa gawai ke sekolah, peserta didik juga sebenarnya tidak diperbolehkan membawa laptop ke sekolah jika tidak ada instruksi dari guru dan hanya jika ada suatu kepentingan (tugas) bersama yang mengharuskan menggunakan laptop di sekolah. Dikhawatirkan terjadi kehilangan jika peserta didik melanggar aturan sekolah.

Kemampuan siswa dalam memanfaatkan teknologi tidak hanya dilihat dari kemampuan siswa dalam mengoperasikan piranti digital saja, tetapi bagaimana siswa dalam memanfaatkan piranti lunak dan sistem yang ada di dalamnya. Siswa juga perlu diajarkan bagaimana menyaring informasi dan berita dengan benar. Mengakses situs-situs resmi yang berkaitan dengan pembelajaran dan membedakan berita hoaks dengan fakta.

b. Memahami dan menimbang kualitas isi dan sumber literasi digital;

Kaitannya dengan pemahaman peserta didik terhadap literasi digital, di SMP Muhammadiyah Pangkalan Bun salah satu kendala realisasi literasi digital adalah keterbatasan perangkat digital. Beberapa fasilitas sekolah yang harus ada di setiap kelas juga belum terpenuhi, mengingat lokasi sekolah yang masih menjadi lalu-lalang masyarakat umum dikhawatirkan perangkat yang sudah terpasang secara baik akan terjadi kehilangan. Hal inilah yang menjadi alasan fasilitas perangkat digital belum tercukupi secara baik, sehingga berdampak pada pengetahuan dan keterampilan siswa dalam memanfaatkan perangkat teknologi secara maksimal.

Kompetensi peserta didik dalam mengoperasikan perangkat digital memang sudah baik, akan lebih baik lagi jika diimbangi dengan pengetahuan peserta didik dalam menyaring informasi dan berita yang masuk. Pengalaman peserta didik dalam menimbang isi informasi perlu dikembangkan lagi dengan memberikan literasi digital secara optimal. Sehingga peserta didik dapat membedakan isi informasi yang akurat.

c. Menganalisis, mengonstruksi dan mengomunikasikan informasi dan pengetahuan yang didapat hasil dari liteasi digital secara baik dan bertanggung jawab.

Mengingat keterbatasan perangkat digital di sekolah, banyak peserta didik yang belum mengetahui perangkat lunak apa saja yang bisa dimanfaatkan sebagai media pengumpulan tugas, dan media belajar mandiri. Hal inilah yang menjadi tugas guru untuk memberikan pengarahan dan pengajaran dalam memanfaatkan sistem perangkat lunak melalui internet. Piranti lunak yang dapat dimanfaatkan dalam pembelajaran yaitu menggunakan aplikasi online seperti schoology dan google clasroom. Apabila peserta didik telah mendapatkan pengetahuan dalam 
menyaring informasi maka tidaklah sulit dalam mendapatkan informasi yang akurat.

Berdasarkan teori Hidayat dan Khotimah (2020:10) pesatnya perkembangan teknologi memberikan pengaruh besar terhadap dunia pendidikan. Pengaruh tersebut menuntut guru untuk dapat memanfaatkan teknologi ke dalam pembelajaran sebagai media digital. Pemanfaatan teknologi ini sebagai faktor munculnya istilah literasi digital yang mendorong pembelajaran aktif menggunakan sistem pemrosesan digital, konstruksi ilmu pengetahuan, pembelajaran inquiri, dan eksplorasi para peserta didik.

\section{Realisasi Gerakan Literasi Digital di SMK Muhammadiyah Pangkalan Bun}

Berdasarkan hasil penelitian, pembelajaran di SMK Muhammadiyah Pangkalan Bun sudah merealisasikan pembelajaran berbasis digital. Perbedaannya di SMK, perlakuan pembelajaran di dalam kelas harus berbeda-beda. Mengingat terbagi ke dalam kelompok jurusan yang berbeda, guru harus menyesuaikan dengan kondisi peserta didik dan bidangnya masing-masing.

Literasi digital lebih kuat terealisasikan di kelas Multimedia. Sekolah menyediakan fasilitas jaringan internet di Kelas Multimedia guna kelancaran proses pembelajaran di kelas tersebut. Peserta didik terampil dalam mengoperasikan perangkat digital dan memanfaatkan piranti lunak secara optimal. Kegiatan ini tercermin ke dalam keterampilan siswa dalam mengedit video. Penugasan yang diberikan oleh guru dapat selesai tepat waktu, mulai dari pengambilan gambar, hingga proses pengeditan.

Perlakuan dalam pembelajaran juga berbeda untuk bidang keahlian farmasi dan pertanian. Di kelas farmasi, Guru perlu menyesuaikan kondisi siswa di kelas tersebut. Guru tidak akan memberikan contoh teks di luar bidang jurusan mereka, guru akan memberikan contoh teks yang berkaitan dengan bidang jurusan mereka agar materi dapat tersampaikan dengan baik.

Berdasarkan penuturan Guru Bahasa Indonesia SMK Muhammadiyah Pangkalan Bun "peserta didik lebih tertarik dengan media audiovisual yang berupa tayangan daripada harus membaca". Hal ini menunjukkan daya baca siswa yang rendah. Untuk meningkatkan daya baca siswa diperlukan pembaharuan dalam kegiatan pembelajaran. Misalnya dengan menciptakan pembelajaran interaktif, pembelajaran di luar kelas, dan model pembelajaran menarik lainnya yang disesuaikan dengan bidang jurusan peserta didik.

Penggunaan media audiovisual juga harus disesuaikan dengan waktu dan bidang keahlian peserta didik. Apabila waktu pelajaran sudah cukup siang dan diimplementasikan di kelas Pertanian maka pembelajaran akan menjadi tidak kondusif. Maka untuk menghindari dampak ini guru perlu melakukan pembaharuan metode, misalnya mengolaborasikan antara keterampilan berbicara dan gerakan. Siswa diajak untuk berdiri dan menyanyi dengan mengubah lirik lagu menjadi teks persuasif. Dengan contoh kegiatan ini akan menggiatkan siswa dan menumbuhkan semangat untuk kembali belajar.

Larangan menggunakan gawai di sekolah tidak menghalangi siswa untuk berkembang. Ada banyak faktor yang menjadi alasan bagi sekolah untuk melarang peserta didik membawa gawai ke sekolah. Tentunya keputusan itu demi tercapainya tujuan pembelajaran dan kelancaran kegiatan belajar di sekolah. 
Berdasarkan penuturan Guru Bahasa Indonesia SMK "dulu pernah diperbolehkan untuk membawa HP, tetapi kenyataannya banyak yang disalahgunakan di sekolah". Hal ini membuktikan bahwa penggunaan teknologi belum dimanfaatkan secara positif, serta kurangnya pemantauan orang tua atas kebutuhan anak. Dalam kasus ini, peran guru di sekolah sangat dibutuhkan, untuk membimbing peserta didik dalam membuka jendela literasi digital agar tidak menyalahgunakan teknologi.

Sudah menjadi kebijakan sekolah dalam mengambil tindakan demi tercapainya tujuan pendidikan. Lain halnya dengan sekolah lain, masing-masing sekolah memiliki cara sendiri dalam mengatasi permasalahan. Larangan membawa gawai ke sekolah juga merupakan langkah yang tepat, namun setiap pilihan pasti mengandung konsekuensi. Bagaimana cara agar dengan larangan tersebut siswa tetap bisa belajar teknologi. Misalnya dengan menyediakan Lab Bahasa lengkap dengan komputer dan piranti pendukungnya. Dengan adanya fasilitas ini siswa tetap belajar dengan baik, mempelajari teknologi, mempelajari sistem, belajar menyaring informasi dengan tepat, dan mengakses situs-situs resmi guna mengurangi penyebaran berita hoaks.

Dengan adanya Lab Bahasa dapat memudahkan guru dalam mengajar. Mengajak peserta didik belajar bahasa dengan menarik, misalnya dengan menggunakan media audiovisual. Peserta didik menjadi tertarik untuk mempelajari bahasa.

Berdasarkan teori Alexander (2020:13) keterampilan digital sangat dibutuhkan dalam proses pembuatan perangkat digital sebagaimana mencakup alat produktivitas kantor; pembuatan, dan pengeditan media (gambar, audio, video); keterampilan web (menulis dan mencari); keterampilan media hardware (perangkat keras komputer, pencetakan 3D); dan bidang yang muncul (VR, AR, MR) tetap berfungsi sebagaimana mestinya. Melihat potensi dan keterampilan siswa dalam mengedit video sudah sangat baik, hal ini terlihat pada hasil editan yang ditampilkan gambar tidak pecah, audio terdengar jelas, efek video terlihat bagus. Bagi peserta didik multimedia pengeditan video menjadi pelajaran inti di jurusannya. Hal ini menjadi nilai tambah bagi peserta didik dalam memproduksi video yang lebih baik lagi. Kelas Multimedia memiliki peluang yang besar untuk menciptakan konten-konten yang bermanfaat, bahkan bisa menjadi peluang usaha di bidang pengeditan media, keterampilan media perangkat keras, percetakan, keterampilan web, dan keterampilan-keterampilan lainnya.

\section{SIMPULAN}

Gerakan literasi digital di Sekolah Muhammadiyah Pangkalan Bun sudah diimplementasikan secara baik namun belum dioptimalisasikan secara sempurna. Literasi digital di Sekolah Muhammadiyah Pangkalan Bun direalisasikan dalam wujud perangkat keras seperti laptop, proyektor, speaker, dan WiFi. Di SMP Muhammadiyah Pangkalan Bun dalam ketersediaan fasilitas tersebut masih sangat terbatas. Sekolah hanya memiliki 1 speaker, 4 unit proyektor, dan 1 WiFi yang diletakkan di ruang guru. Sehingga dalam penggunaannya harus secara bergantian. Sedangkan di SMK Muhammadiyah Pangkalan Bun internet disediakan oleh sekolah yang hanya bisa diakses di kelas Mulitmedia. Karena kebutuhan peserta didik kelas Multimedia sangat penting demi kelancaran pembelajaran di kelas tersebut. Dalam pembelajaran, tidak semua jurusan di SMK Muhammadiyah Pangkalan Bun 
menggunakan peralatan digital, hanya jurusan Multimedia dan mata pelajaran Multimedia saja yang diutamakan menggunakan peralatan digital.

Terlepas dari keterbatasan, Sekolah Muhammadiyah Pangkalan Bun memberikan peluang bagi semua peserta didik untuk terus mengembangkan kompetensi dan keterampilannya di bidang teknologi. Melalui kegiatan belajar berbasis digital sudah mencerminkan pembelajaran yang menarik dan menyenangkan. Dalam hal ini sekolah sudah bergerak menuju literasi digital.

\section{DAFTAR PUSTAKA}

Alexander, B., Adams Becker,S., \& Cummins, M. (2016). Digital Literacy: An NMC Horizon Project Strategic Brief. Volume 3.3, October 2016. Austin, Texas: The New Media Consortium.

Alexander, B., Adams Becker,S., Cummins, M., \& Hall Giesinger, C. (2017). Digital Literacy in Higher Education, Part II: An NMC Horizon Project Strategic Brief. Volume 3.4, August 2017. Austin, Texas: The New Media Consortium.

Ali, Mohamad. (2017). Menyemai Guru Muhammadiyah Berkemajuan di Sekolah Muhammadiyah. Ishraqi, 1(1), 31-39.

Atmazaki dkk. (2017). Panduan Gerakan Literasi Nasional. Jakarta: Kementerian Pendidikan dan Kebudayaan.

Ginanjar, Asep dkk. (2019). Implementasi Literasi Digital dalam Proses Pembelajaran IPS di SMP Al-Azhar 29 Semarang. Harmony, 4(2), 99-105.

Gracia, Anne dkk. (2018). Seri Pendidikan Orang Tua: Mendidik Anak di Era Digital. Jakarta: Kementerian Pendidikan dan Kebudayaan.

Harjono, Hary Soedarto. (2018). Literasi Digital: Prospek dan Implikasinya dalam Pembelajaran Bahasa. Pena, 8 (1), 1-7.

Hidayah, Layli., Widodo, Ganjar Setyo \& Sueb. (2019). Revitalisasi Partisipasi Masyarakat dalam Gerakan Literasi Nasional: Studi pada Program Kampung Literasi. Jurnal Bidang Pendidikan Dasar, 3(1): 87-98.

Hidayat, Nanang \& Khotimah, Husnul. (2019). Pemanfaatan Teknologi Digital dalam Kegiatan Pembelajaran. Jurnal Pendidikan dan Pengajaran Guru Sekolah Dasar, 2(1), 10-15.

Ibrahim, Gufran Ali dkk. (2017). Peta Jalan Gerakan Literasi Nasional. Jakarta: Kementerian Pendidikan dan Kebudayaan.

Kajin, Sudar. (2018). Pengaruh Pembelajaran Berbasis Literasi Digital Terhadap Motivasi Dan Hasil Belajar Kognitif di MTs N Mojosari dan MTs N Sooko Mojokerto. PROGRESSA Journal of Islamic Religious Instruction, 2 (1), 133-142.

Koesoema, Doni dkk. (2017). Pedoman Penilaian dan Evaluasi Gerakan Literasi Nasional. Jakarta: Kementerian Pendidikan dan Kebudayaan. 
Liansari, Vevy \& Nuroh, Ermawati Z. (2018). Realitas Penerapan Literasi Digital bagi Mahasiswa FKIP Universitas Muhammadiyah Sidoarjo.Proceedings of The ICERS, 1(3), 241-252.

Marlina, Leny. (2012). Kajian Terhadap Perkembangan Sekolah Muhammadiyah. Ta'dib, $17(1), 103-124$.

Nasrullah, Rullie dkk. (2017). Materi Pendukung Literasi Digital. Jakarta: Kementerian Pendidikan dan Kebudayaan.

Pangrazio, Luciana. (2016). Reconceptualising critical digital literacy.Discourse: Studies in the Cultural Politics of Education, 37(2), 163-174.

Rohmadi, Muhammad \& Nasucha, Yakub. (2017). Dasar-dasar Penelitian Bahasa, Sastra, dan Pengajaran. Surakarta: Pustaka Briliant.

Stefany, Stella., Nurbani., \& Badarrudin. (2017). Literasi Digital dan Pembukaan Diri: Studi Korelasi Penggunaan Media Sosial Pada Pelajar Remaja di Kota Medan. SOSIOGLOBAL : Jurnal Pemikiran dan Penelitian Sosiologi, 2(1), 11-31.

Syaripudin, Acep dkk. Kerangka Literasi Digital Indonesia. https://gln.kemdikbud.go.id/gInsite/wp-content/uploads/2019/04/4.-Seri-BukuLiterasi-Digital-Kerangka-Literasi-Digital-Indonesia.pdf

Yusra, Nelly. (2018). Muhammadiyah: Gerakan pembaharuan Pendidikan Islam. Potensia:Jurnal Kependidikan Islam, 4(1), 103-125. 